\title{
Accurate automated leucocyte differential counts despite profound leucopenia
}

\author{
SALLY E KINSEY, M J WATTS Middlesex Hospital, London
}

SUMmARY The differential white cell counts produced by the Technicon $\mathrm{H}^{*} 1$ Autoanalyser in profoundly leucopenic specimens were compared with those carried out by manual differential counting by light microscopy of peripheral blood smears stained with May-Grünwald-Giemsa stain. The correlation achieved allowed the $\mathrm{H}^{*} 1$ derived differential count to be reported with confidence.

An automated cell counter that could produce an accurate differential white cell count in the presence of profound leucopenia $\left(<1.0 \times 10^{9} / 1\right)$ would not only have important implications for the management of haematological malignant diseases, but also save a lot of time in the laboratory.

That automated cell counters can produce accurate and reproducible total white cell counts is well known, even when total leucocytes are as low as $<0.5 \times 10^{9} / 1$. Their ability to provide differential counts in severely leucopenic specimens, however, and the quality of the results obtained are much less satisfactory. The Technicon $\mathrm{H}^{*} 1$ Autoanalyser produces a differential white cell count by cytochemical methods from $100 \mu \mathrm{l}$ of peripheral blood in all cases in which it produces a total white cell count.' In order to establish the accuracy of the differential count obtained from the $\mathrm{H}^{* 1}$ in profoundly leucopenic specimens, we compared the results from the $\mathrm{H}^{*} 1$ with those from manual differential counts carried out microscopically on May-Grünwald-Giemsa stained smears of the same peripheral blood.

\section{Material and methods}

A total of 111 specimens of blood from leucopenic patients who had total white cell counts of $<1.0 \times 10^{9} / 1$ on the Technicon $\mathrm{H}^{*} 1$ Autoanalyser were also analysed by the Coulter S + IV automated cell counter, and by a 100 cell manual differential count performed microscopically on May-GrünwaldGiemsa stained peripheral blood smears, the usual procedure in our laboratory. (Some of the specimens were too leucopenic to perform 100 cell differential counts, and so the differentials were calculated on 50 cells in 13 cases, 25 cells in 12 cases, 20 cells in one case, and 10 cells in two cases.) Using the total white count obtained by the $\mathrm{H}^{*} 1$, the manual different percentages were converted to absolute numbers. The results were analysed using linear regression analysis and a signed rank test.

The $\mathrm{H}^{*} 1$ is a recently developed automated cell counter that produces a five part differential cell count by enumerating cells in two separate detection channels each using different methods, as previously described. ${ }^{23}$ Briefly, the peripheral white cell count is analysed by two counting channels simultaneously; in one channel (the peroxidase channel), discrete cell populations are identified by comparison of light scatter (an indication of cell size) and of optical density of endogenous alkaline peroxidase, the results of which are plotted on a cytogram. In the other channel, the basophil lobularity channel, the cytoplasmic membrane of all cells except basophils (which are resistant) are lysed and the nuclei are enumerated and sized by measurement of forward angle light scatter of laser light, which identifies the basophil population and permits some assessment of nuclear lobularity (and hence maturity) to be made. Thus the five part differential is obtained.

The $\mathrm{H}^{*} 1$ also includes in the differential count those cells that comprise an otherwise morphologically difficult population of cells to categorise, but that are identified on the $\mathrm{H}^{*} 1$ peroxidase channel cytogram as large unstained cells (LUCs) because of their size and low or absent endogenous peroxidase activity. These cells look monocytoid on light microscopy, and are usually encompassed either within the lymphocyte or monocyte part of the manual differential count. These cells are present in considerable numbers in the peripheral blood of patients recovering from cytopenia induced by chemotherapy, and also in 
patients who have received autologous or allogeneic bone marrow transplants. The increase in LUCs has been recognised as a marker of impending reconstitution of bone marrow in these groups of patients. ${ }^{3-5}$

As the two counting channels are analysing the same peripheral blood simultaneously, any large discrepancy between the total cell count derived from each channel prevents the $\mathrm{H}^{*} 1$ computer recording a result and only the total white count and differential from the peroxidase channel is used. As long as the two counting channels do not show a large discrepancy between results obtained, a differential is produced in all cases.' This is an important advantage over other automated cell counters.

\section{Results}

Signed rank tests were performed on all measurements: total white cell count $\left(\mathrm{H}^{*} 1\right.$ compared with S + IV), neutrophils, lymphocytes, and monocytes. The results were not significant, the $95 \%$ confidence intervals showing considerable overlap, except for those for lymphocytes, which did not overlap and implied that manual differential counting gave higher counts than the $\mathrm{H}^{*}$. The differences, however, were small. Linear regression analysis gave high positive correlation in all cases (except for basophils) and the line of best fit passed through or close to the origin in all cases, implying that $x=y$ and that the counts derived by each method are similar.

The results obtained by linear regression analysis of the Technicon $\mathrm{H}^{*} 1$ total white count and the Coulter $S+I V$ total white count gave a value of $r=0.85$; this is good correlation.

The results of linear regression analysis for each part of the white cell differential, comparing $\mathrm{H}^{*} 1$ differen-

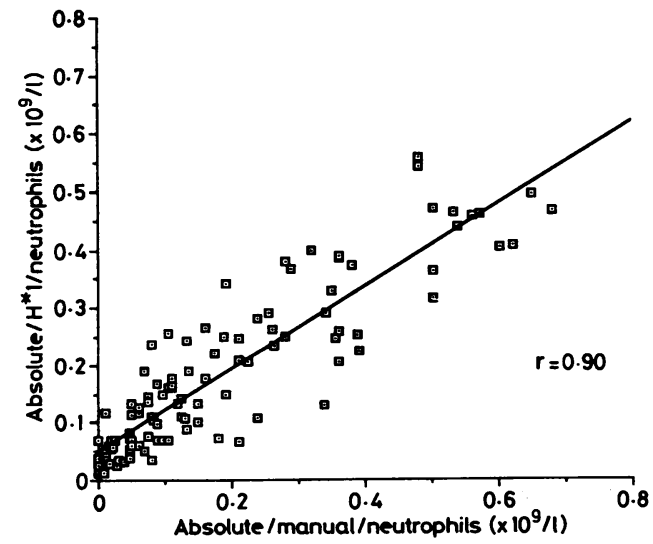

Fig 1 Scatter plot of absolute neutrophil count, $\mathrm{H}^{*} \mathrm{I}$ compared with manual.

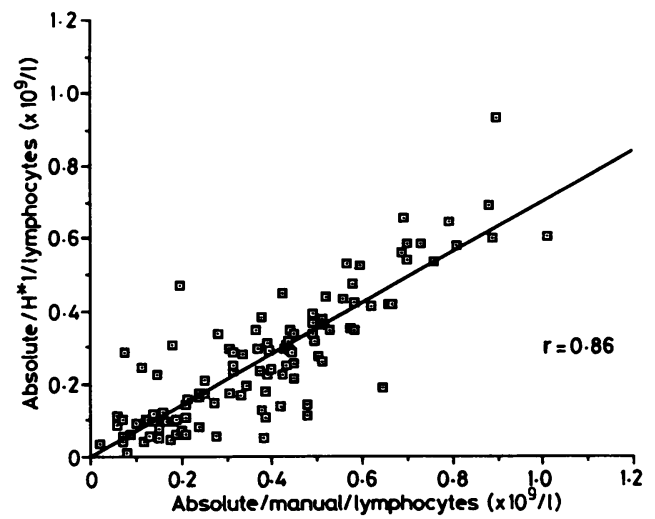

Fig 2 Scatter plot of absolute lymphocyte count, $H^{*} I$ compared with manual.

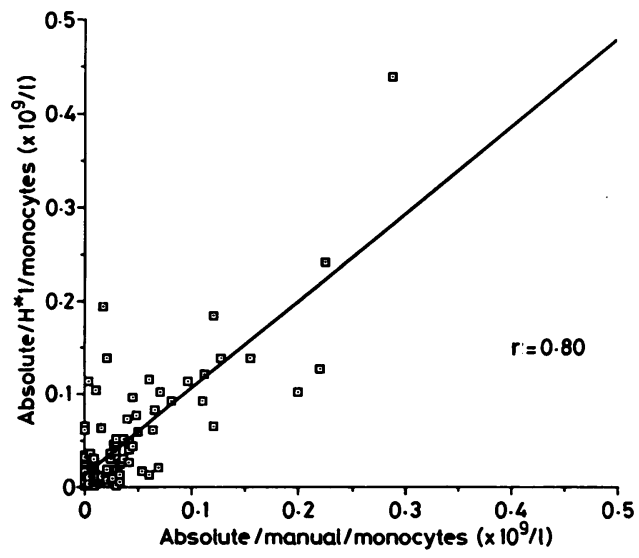

Fig 3 Scatter plot of absolute monocyte count, $H^{*} 1$ compared with manual.

tial results with microscopic manual results, are shown as scatter plots (figs 1, 2, and 3).

The correlation coefficients show good correlation: neutrophils, $r=0.90$; lymphocytes, $r=0.86$; and monocytes, $r=0.80$. The linear regression analyses for the results obtained for eosinophils and basophils show less correlation between the two methods $(r=0.85$ and $r=0.25$, respectively); these plots are not shown. The main reason for this discrepancy is that on a 100 cell differential count in leucopenic patients the prevalence of these cells is low, hence they seldom enter the manual differential. The $H^{*} 1$, however, is counting many more cells and thus the few eosinophils and basophils enumerated actually form part of the differential count. 


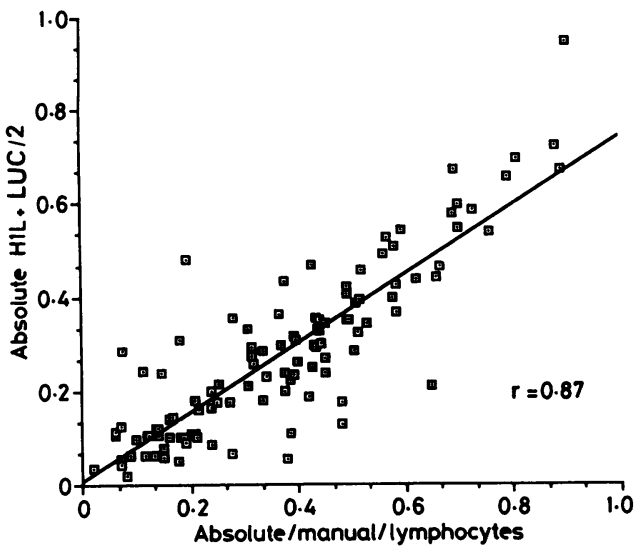

Fig 4 Scatter plot of absolute $H^{*} 1$ lymphocyte count plus $50 \%$ of the absolute large unstained cell count compared with absolute manual lymphocyte count.

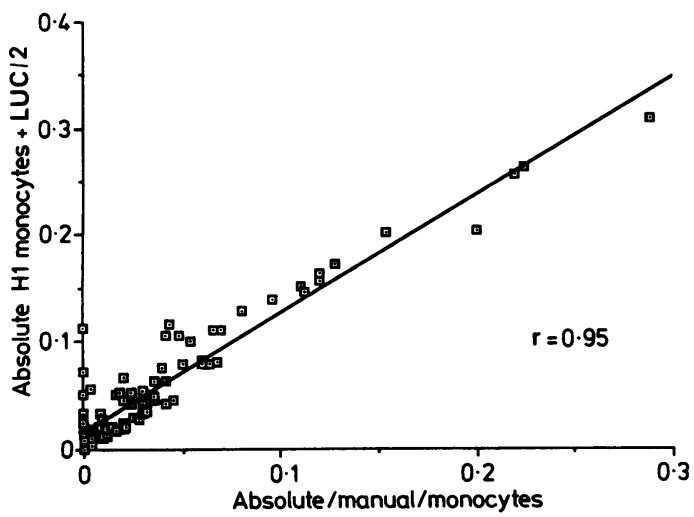

Fig 5 Scatter plot of absolute $H^{*} I$ monocyte count plus $50 \%$ of the absolute large unstained cell count compared with absolute manual monocyte count.

The only part of the $\mathrm{H}^{*} 1$ differential thus far not scrutinised is that of the LUCs. The LUCs are difficult cells to categorise morphologically, as they have monocytoid, lymphoid, and blastic characteristics microscopically. On manual differential counting LUCs are likely to be included in the blast cell category if they display immature characteristics (there were no true blast cells in this series), or be regarded as monocytes or large lymphocytes. As these cells appear "monocytoid" but with some lymphoid characteristics we arbitrarily divided the number of LUCs by two, and added each $50 \%$ to the total number of monocytes or lymphocytes already calculated. Thus a scatter plot of $\mathrm{H}^{*} 1$ lymphocytes $+(\mathrm{LUC} / 2)$ was plotted against manual lymphocytes, $(r=0.87)$, (fig 4), and similarly, $\mathrm{H}^{*} 1$ monocytes plus (LUC/2) against manual monocytes $(r=0.95)$, (fig 5$)$. This manoeuvre resulted in improvement of the correlation coefficients, and permitted more rapid interpretation of the $\mathrm{H}^{*} 1$ derived differential.

In all cases (excluding the basophils), there was high positive correlation. Importantly, the intercept was almost through the origin in all cases, implying that counts derived by both methods were similar. As far as the lymphocyte and monocyte plots are concerned this discrepancy improved when $50 \%$ of the $\mathrm{H}^{*} 1$ measured LUC count was added to the $\mathrm{H}^{*} 1$ results for lymphocytes and monocytes, respectively; this provided further evidence that the cell population identified by the $\mathrm{H}^{*} 1$ as LUCs are a difficult group to define morphologically.

\section{Discussion}

The results that we have obtained from this small study are encouraging. That the signed rank test showed no significant differences implies that the two different methods compare favourably, thus making both results equally reliable.

The need for accurate differential white cell counts in profoundly leucopenic patients is an important part of the management of patients undergoing treatment of haematological malignant diseases. The risk of infection in this group of patients is proportional to the absolute neutrophil count ${ }^{6}$ and particularly great when the total neutrophil count falls below $0 \cdot 5=10^{9} / 1$.

The assurance that the $\mathrm{H}^{*} 1$ derived differential white cell count correlates to such a high degree with the manual differential frees laboratory technical staff from the painstaking task of performing time consuming manual differential counts that often take more than 20 minutes for each specimen. Thus an automated counter that provides such saving of labour is an important asset in a busy laboratory serving a large haematology/oncology unit.

We believe that this study provides the evidence that the Technicon $\mathrm{H}^{*} 1$ autoanalyser produces sufficiently accurate differential white cell counts for important clinical decisions in the management of profoundly leucopenic patients to be made.

This study was undertaken using peripheral blood specimens obtained from patients rendered pancytopenic by treatment for haematological malignant diseases. All these patients were in remission, and none had any evidence of circulating blast cells. We believe, however, that the use of the $H^{*} 1$ autoanalyser differential count need not be restricted to patients such as those in this study, but may be useful in the management of any leucopenia whatever the cause. 


\section{References}

1 Technicon $\mathrm{H}^{*} 1$ System Operators Guide, Tarrytown: Technicon Instruments, 1986.

2 D'Onofrio G, Mancini S, Leone G, Bizzi B, Mango G. Identification of blast cells in peripheral blood through automatic assessment of nuclear density: a new tool for the monitoring of patients with acute leukaemia. Br J Haematol 1987;66:473-8.

3 Kinsey SE, Carter AB, Watts MJ, Goldstone AH, Machine SJ. The use of the $\mathrm{H}^{*} 1$ in predicting marrow recovery following ablative chemotherapy in leukaemia and lymphoma. Clin Lab Haematol 1988;10;1-7.

4 Martin PJ, Anderson CC, Jones HM, Lai AP, Linch DC, Goldstone AH. A rise in the percentage of large unstained cells in the peripheral blood determined by the Hemalog D90 automated differential counter is a feature of impending myeloid engraftment following bone marrow transplantation. Clin Lab Haematol 1986;8:1-8.

5 Linch DC, Knott LJ, Thomas RM, et al. T-cell regeneration after allogeneic and autologous bone marrow transplantation. $\mathrm{Br} J$ Haematol 1983;53;451-8.

6 Bodey GP, Buckley M, Sathe YS, Friereich EJ. Quantitative relationships between circulating leukocytes and infection in patients with acute leukaemia. Ann Intern Med 1966;64:328-40.

Requests for reprints to: Dr S E Kinsey, Department of Haematology, The Middlesex Hospital, Mortimer Street, London, WIN 8AA, England. 